\title{
Hannah Arendt: da ação nas tragédias gregas aos conselhos revolucionários
}

\section{Hannah Arendt: from action in the Greek tragedies to revolutionary coun- cils}

DOI: $10.20873 /$ rpv6n2-07

\section{Carlos Fernando Brito SIlva}

Orcid: 0000-0002-5496-7138

Email: semfernand@gmail.com

\begin{abstract}
Resumo
O presente texto objetiva explorar a possibilidade de correspondência entre os elementos extraídos por Arendt na leitura de Homero e da fonte trágica grega, e àqueles percebidos pela autora nos sistemas de conselhos. Para tanto, este ensaio fará um primeiro movimento de compreensão da interpretação que Hannah Arendt faz da figura do herói homérico e suas implicações para seu conceito de ação não soberana e em seguida uma exposição de sua leitura sobre os sistemas de conselho destacando a importância que a autora dá ao surgimento espontâneo dessas experiências. Com isso não se pretende reforçar as críticas feitas de quer Hannah Arendt é uma pensadora nostálgica, mas explorar o tema das fontes do seu pensamento destacando a singularidade do mesmo que consiste em pensar o impensado pela tradição.
\end{abstract}

\section{Palavras-chave}

Ação não soberana. Sistemas de conselho. Trágico grego.

\begin{abstract}
The present text aims to explore the possibility of correspondence between the elements extracted by Arendt in her reading of Homer and the Greek tragic source, and those perceived by the author in the council systems. In order to do so, this essay will first understand Hannah Arendt's interpretation of the figure of the hero in Homer and its implications for her concept of non-sovereign action. This is not intended to reinforce the criticism that Hannah Arendt is a nostalgic thinker, but to explore the theme of the sources of her thought, highlighting its singularity which consists in thinking the unthought by tradition.
\end{abstract}

\section{Keywords}

Non-sovereign action. Council systems. Greek tragic. 

nada enche a vida. A vida é viver."

(Ferreira Gullar)

No decorrer do seu caminho filosófico entorno da busca pelo sentido da política, Hannah Arendt defronta-se diretamente com a problemática que ela chamou de "ruptura da tradição": a incapacidade das categorias tradicionais do pensamento político ocidental de responderem a eventos modernos, tais como guerras, avanço tecnológico e problemáticas de relações internacionais envolvendo o aumento de poderio bélico das nações. Diante deste fato, a pensadora interpõe em seu pensamento um diálogo constante com o conteúdo e experiências filosóficas da antiguidade, a fim de oferecer um reexame das categorias tradicionais da filosofia política. Essa empreitada arendtiana é ainda alvo de críticas, sendo a pensadora por vezes descrita como "anacrônica", "nostálgica" e/ou "grecomaníaca".

A pensadora pôde enxergar nesses "eventos antigos" aspectos originários da política que foram negligenciados pela tradição, partes do que podemos denominar como uma tradição impensada. Toda ação política é feita por sujeitos, ou seja, por pessoas capazes de atos e palavras. A relação entre os sujeitos das revoluções modernas e as experiências políticas da antiguidade é um dos fenômenos que faz Arendt voltar seu olhar para as revoluções modernas e enxergar a insurreição desse "impensado" diante da tradição.

Neste texto desenvolve-se, mesmo de modo propedêutico, a hipótese de que os elementos que Arendt extrai da sua leitura sobre Homero e fonte trágica grega para pensar a apolítica, ganham uma expressão contemporânea a partir da leitura que a autora faz do sistema de conselhos oriundos das revoluções modernas. A fim de elucidar essa compreensão faremos aqui uma abordagem da aproximação de Arendt com a fonte trágica e em seguida uma exposição sobre o olhar da pensadora sobre os conselhos, destacando especialmente a primazia da espontaneidade e como isso liga os dois momentos. 


\section{Ação "heroica" do homem livre}

A importância da figura do herói homérico para Hannah Arendt, componente importante da fonte trágica grega, denota da definição que a pensadora faz do que seria a ação política. Conforme a pensadora, "agir, em seu sentido mais geral, significa tomar iniciativa, iniciar (como indica a palavra grega archein, "começar", "conduzir" e, finalmente, "governar"), imprimir movimento a alguma coisa (que é o significado original do termo latino agere)" (ARENDT, 2016a, p. 219). Essa definição ${ }^{1}$ possui uma correlação direta com as leituras de Arendt do sentido da política conforme apresentado pelos antigos. A raiz da estima destes para com a política se dá mediante a compreensão de que somente através dos elementos da política (ação e discurso) os homens enquanto homens podem perdurar sua existência através das capacidades narrativas intrínsecas a política (ARENDT, 2016a, p. 257).

Arendt compreende que a ação e o discurso, elementos da política, sofrem de uma futilidade material, ou seja, não possuem resultado tácito que possa "validar a sua existência". Para enfrentar tal problema é que Arendt usa a imagem metafórica da sociedade como um anfiteatro, ou seja, um espaço que possui o testemunho ocular das pessoas capazes de construir uma narrativa. Estes são traços que são mais bem esclarecidos a partir da aproximação da autora com a literatura homérica.

O processo de singularização dos sujeitos, agentes da polis, passa por essa capacidade de distinção através de atos e palavras que são acompanhados e/ou testemunhados por seus pares. Conforme Francisco, essa leitura de Arendt possui fortes raízes na tradição homérica. Nas palavras da autora,

Na Odisséia, no episódio em que Ulisses deixa a ilha de Calipso (canto V), podemos ver com clareza a que Arendt se refere quando afirma que uma das descobertas dos guerreiros épicos dizia respeito à

\footnotetext{
1 “Aos dois verbos gregos archein ('começar' 'liderar' e, finalmente 'governar') e prattein ('atravessar', 'realizar' e 'acabar') correspondam os dois verbos latinos agere ('pôr em movimento', 'liderar') e gerere (cujo significado original é 'conduzir')" (ARENDT, 2016a, p. 234); A importância desse esclarecimento linguístico é destacado por Rodrigo Alves Neto nos seguintes tempos: "Arendt se vale das distinções que as línguas grega e latina estabelecem para o termo ação. [...] Essas duas acepções correspondentes em grego e latim fazem Arendt crer que a ação estaria dividida em duas partes: o começo feito por um só agente e a realização, à qual muitos aderem para "conduzir", dar "acabamento". [...] A falácia do homem poderoso por estar só provém do fato de que o iniciador está só apenas na sua iniciativa e nos riscos que assume, mas não na realização do ato, que sempre depende de muitos" (ALVES NETO, 2009, p. 83.)
} 
possibilidade de uma existência humana dotada de máxima realidade. Antes de chegar à ilha de Calipso, Ulisses tinha executado feitos inigualáveis, dos quais ninguém, exceto ele próprio, tinha conhecimento. Não tivesse ele deixado Calipso e se tornado aedo de suas próprias façanhas, seria como se estas nunca tivessem ocorrido e ele estivesse morto, tal como de fato era dado por todos. Ulisses só se torna real, isto é, efetivamente vivo para o mundo, quando relata seus feitos. Assume, além disso, um grau máximo de realidade por narrar atos de tal grandiosidade que permanecerão na memória dos ouvintes por muito tempo. (FRANCISCO, 2013, p. 191)

Muito dessa passagem que fora sinteticamente comentada por Maria de Fátima Francisco liga-se a todas as outras de Arendt que dizem respeito à ação e ao agente. Apesar de a ação ser descrita como algo que padece por carência material, Arendt apresenta a possibilidade de durabilidade dessas atividades no interior delas próprias. De igual modo, conforme narrado, o perduro das ações de Ulisses passam pela capacidade dele de torná-las conhecidas (aparecer) aos demais cidadãos. Esses feitos heroicos que foram realizados na privacidade de Ulisses só se tornam reais quando relatados; somente aí eles podem adquirir o grau máximo de realidade. Do mesmo modo, segundo Arendt, a existência humana é plenificada somente no espaço público e assim dizemos que a existência humana só adquire um grau máximo de realidade na medida em que aparece aos demais através de atos e palavras.

Essa reflexão põe em xeque os pressupostos utilizados pela antiguidade para validar, ou não, o pertencimento de determinados atos ao campo da política. Para compreender esses pressupostos, faz-se preciso abordarmos a existência de uma "dualidade existencial" presente na antiguidade, a saber, a relação entre imortalidade e os mortais. Temos através dos relatos mitológicos o conhecimento do convívio frequente entre entidades imortais com seres mortais ${ }^{2}$. Conforme Arendt, denota-se aí a existência de uma espécie de paradoxo que sem dúvidas estivera na mente dos principais teóricos da política, da historiografia e a da poesia da Grécia antiga. 0 paradoxo consiste em "[...] que, por um lado tudo era visto e medido contra o pano de fundo das coisas que existem para sempre, enquanto, por outro, a verdadeira grandeza humana

\footnotetext{
2 Por mortalidade Arendt entende o "[...] mover-se ao longo de uma linha retilínea em um universo onde tudo, se é que se move, se move em uma ordem cíclica. Sempre que os homens perseguem seus objetivos, lavrando a terra rude, forçando em suas velas o vento que flui livre e cruzando vagas constantemente encapeladas, eles seccionam transversalmente um movimento que é desprovido de objetivo e encerrado dentro de si mesmo" (ARENDT, 2014, p. 71).
} 
era [...], compreendida como residindo em feitos e palavras [...]" (ARENDT, 2002, p. 75). Courtine-Denamy afirma:

\begin{abstract}
Os gregos já sabiam que, em meio a um universo imortal, os homens seriam os únicos 'mortais', ou seja, os únicos a se moverem em linha reta ante um universo cíclico. Mas reconheciam também que, aparentados aos deuses, com quem dividiam a natureza divina, os homens teriam recebido deles a aptidão para ações imortais. Se a atividade divina, em Homero, é a contemplação do espetáculo do mundo, esta paixão também seria própria aos homens. Em revanche, para os romanos, é a aptidão para fundar e governar cidades que seria divina, assim como a política e as res publica seriam a garantia contra a futilidade da vida individual. Em ambos os casos, para compensar a inferioridade de suas características como mortais, os homens devem realizar ações susceptíveis de lhes conferir o prazer da imortalidade. (COURTINE-DENAMY, 2004, p. 182-183)
\end{abstract}

O confronto diário entre a necessidade de tornar imortais os frutos de seres mortais em contraponto com a eternidade de seres divinos fora de grande valia para dar à política - a esfera própria dos atos e palavras - a dignidade redentora dessa mortalidade humana, visto que "indo sempre em direção à morte, a vida do homem arrastaria consigo, inevitavelmente, todas as coisas humanas para a ruína e para a destruição [...]" (ALVES NETO, 2009, p. 79). Chama atenção que Arendt insere esse paradoxo no campo da inquietude dos filósofos. Isto pode ser atribuído ao fato de que tradição metafísica e política posterior a Platão defrontou-se com o problema da imortalidade e eternidade e não involuntariamente, quase sempre refugiou-se na substituição da fragilidade da ação pela durabilidade da fabricação.

Para Homero, a imortalidade humana estava longe da fabricação e mais distante ainda do mero trabalho biológico, naturalmente pertencente à vida privada. Diante disto, “[...] a solução para o problema [da forma de alcançar a imortalidade] já transparece em seus próprios dados, isto é, o que faz dos homens os únicos mortais, os fará também imortais" (FRANCISCO, 2013, p. 194, acréscimo nosso), ou seja, na capacidade de relacionar-se e erigir um espalho de liberdade e ação plural reside a possibilidade de galgar-se a imortalidade.

Essa busca por um meio de imortalizar-se ressoa ainda na filosofia de Aristóteles, de modo mais objetivo nas suas considerações sobre o bios politikos, esse segundo modo de vida, não-natural que distingue os homens uns dos outros. Essa concepção aristotélica é ainda resultado da figura do herói homérico. 
Descrevendo o quem da figura do herói apresentada por Homero, Arendt, através do exemplo de Aquiles, afirma que "a estatura do Aquiles homérico só pode ser compreendida quando se o vê como 'o realizador de grandes feitos e o pronunciador de grandes palavras'” (ARENDT, 2016a, p. 31; ARENDT, 2016b, p. 91). Essa descrição de Aquiles pautada no binômio ação e palavra é própria de Homero, em sua obra Ilíada ${ }^{3}$. Arendt percebe nessa definição a capacidade dos homens de galgar a imortalidade ofertada pela participação nos assuntos públi$\cos$.

"Por sua capacidade de realizar feitos imortais, por poderem deixar atrás de si vestígios imorredouros, os homens, a despeito de sua mortalidade individual, atingem a imortalidade que lhes é própria e demonstram sua natureza divina" (ARENDT, 2016a, p. 24). Conforme já fora exposto, essa imortalidade ${ }^{4}$ está centrada diretamente na capacidade para agir. Todavia, ao contrário do que é pontuado por alguns críticos, como Peter Euben, O’Sullivan e Jürgen Habermas, o emprego da figura do herói homérico nas relações políticas não é uma introdução de padrões absolutos, metafísicos e/ou divinos na esfera dos assuntos humanos. Segundo as palavras de Arendt,

[...] em Homero, a palavra "herói" não era mais que um nome dado a qualquer homem livre que houvesse participado da aventura troiana e do qual se podia contar uma história. [...] Em Homero, a palavra heros sem dúvida tinha uma conotação de distinção, mas uma distinção de que era capaz qualquer homem livre. Em parte alguma aparece com o significado ulterior de "semideus", resultante talvez da definição dos antigos heróis épicos. (ARENDT, 2016a, p. 231)

Esclarecendo esses fatos, nossa pensadora destaca que o herói, conforme concebido por Homero, não era alguém que gozava de uma predisposição natural para a realização de proezas e façanhas, como os semideuses da mitologia, mas era, na verdade, alguém capaz de gozar da

\footnotetext{
${ }^{3}$ Cf. Ilíada, xi, 443.

${ }^{4}$ Quanto ao que pode levar o homem a atingir essa imortalidade, Arendt afirma: "a língua grega não faz distinção entre "obras" e "feitos", mas chama-os de erga quando são duráveis o bastante para subsistirem e grandiosos o bastante para serem lembrados. Foi somente quando os filósofos, ou melhor, os sofistas, começaram a fazer suas "distinções intermináveis" e a distinguir fazer de agir (poiein e prattein) que os substantivos poimata e pragmata passaram a ser usados mais largamente (Cf. Platão, Cámides, 163). Homero ainda não conhece a palavra pragmata, que em Platão [...] é mais bem traduzida como "negócios humanos" e tem a conotação de inquietação e futilidade" (ARENDT, 2016a, p. 24).
} 
liberdade, galgando a participação nos assuntos humanos e, consequentemente, a sua distinção diante dos demais homens ${ }^{5}$.

Mesmo sendo todos os homens capazes de agir, não necessariamente todos conseguiriam exercer essa faculdade, muitos ficavam apenas na esfera comportamental, ou presos às necessidades da vida privada. Assim, a figura do herói torna-se crucial para a compreensão dessa perspectiva de uma capacidade da ação que era exclusiva aos humanos, porém, não era necessariamente natural, do mesmo modo como fora sintetizado por Aristóteles na sua definição do bios politikos. Sobre a incapacidade dos deuses de agir, Arendt percebe como surpreendente o fato de que eles "[...] só ajam no tocante aos homens, governando-os de longe ou interferindo nos assuntos deles" (ARENDT, 2016a, p. 28). Isto ressalta ainda mais a concepção antiga sobre a natureza política da ação.

Na busca pelo sentido originário da política, a figura do herói é um apoio para a compreensão da verdadeira dignidade do agir político. Apesar de a tradição ter preferido padrões ligados à fabricação para pensar a constituição dos corpos políticos, a consciência implícita desses componentes heroicos da ação sempre esteve presente. Esses elementos que conferem a dignidade do agir político conduzem Arendt a perceber a singularidade de experiências novas que surgiram nas revoluções modernas, a saber: a espontaneidade dos conselhos.

\section{O surgimento dos conselhos nas revoluções}

Sobre os conselhos revolucionários, Arendt dedica as últimas páginas de Sobre a revolução, descrevendo-os exclusivamente como um "tesouro perdido". Porém, essa é uma reflexão que já aparece em textos anteriores: nas reflexões sobre os judeus e a tentativa de construção de um Estado nacional judaico, em $A$ condição humana, quando fala dos movimentos dos

\footnotetext{
5 "O herói homérico alçava distinção quando realizava feitos e discursos que sobrepassavam os dos companheiros em grandiosidade e eram por isso imortalizados pelo poeta. A vida heroica e a vida política por ela modelada trarão em si as condições de sua imortalização porque são plenas de atos e palavras inesquecíveis, tanto para os espectadores, quanto para os pósteros. [...] A única qualidade obrigatória que a ação heroica deveria apresentar era a grandiosidade, isto é, o ultrapassamento das condutas padronizadas, denominadas por Arendt de 'comportamento'. A ação se distingue do comportamento por ser a realização do extraordinário. E era apenas pelo desdobramento da ação assim entendida que se tornava possível a individualização do que participava na aventura troiana" (FRANCISCO, 2013, p. 194; p. 195).
} 
trabalhadores, em suas análises sobre a Revolução Húngara de 1956, e em suas leituras sobre os movimentos estudantis do fim da década de 60. Tomando isso como ponto de partida, acreditamos ser indispensável uma leitura dos conselhos tomando como pano de fundo não apenas as revoluções do século XVIII, mas também à luz desses elementos extraídos da aproximação de Arendt com a fonte trágica de Homero.

A revolução para Arendt possuía uma dupla incumbência: (a) fundar um novo corpo político e (b) "[...] assegurar a sobrevivência daquele espírito de onde brotou o ato fundador, materializar o princípio que o inspirou" (ARENDT, 2011, p. 171). No expecto de compreensão dos eventos revolucionários modernos a partir dessa dupla tarefa Arendt descobre novas expressões dos conselhos e desse modo de ação tipicamente política.

Para Arendt é explicito o fato de que as Constituições revolucionarias ignoraram a existência, no curso das revoluções, “[...] de uma nova forma de governo que guardava uma semelhança assombrosa com o sistema distrital de Jefferson e parecia se repetir, em todas as circunstâncias [...]" (ARENDT, 2011, p. 321). Essa nova forma de governo estava atrelada às sociedades revolucionarias e aos conselhos municipais que frequentemente se alastravam por todo movimento revolucionário que se insurgisse. Vendo nestes conselhos um lugar de preservação e exercício da “[...] liberdade pública, felicidade pública e espírito público" (ARENDT, 2011, p. 283).

Arendt, à luz da ação heroica e desinteressada, destaca o fato de essas estruturas populares surgirem sempre de modo espontâneo como uma das principais características da dimensão política dos conselhos. Os membros dessas estruturas de participação ativa entendiam que seus "únicos objetivos eram [...], 'instruir, esclarecer seus colaboradores sobre os verdadeiros princípios da Constituição, e difundir uma luz sem a qual a Constituição não será capaz de sobreviver"' (ARENDT, 2011, p. 303). A autora chama ainda atenção para o fato de que o surgimento desses conselhos não decorre da práxis partidária, o que nos possibilita especular que talvez decorressem de tradições de pensamento que foram acessadas pelos revolucionários. Contudo, Arendt também acredita ser pouco provável que isso seja verídico. A pensadora afirma que “[...] não se pode invocar nenhuma tradição, revolucionária ou pré-revolucionária, 
para explicar o surgimento e ressurgimento metódico do sistema de conselhos desde a Revolução Francesa" (ARENDT, 2011, p. 328).

Isso porque além de ser uma vivência inteiramente nova, jamais datada pelas tradições de pensamento político, os conselhos funcionavam sem precisar apoiar-se em estruturas já pensadas, de modo que a cada reaparecimento dessa estrutura popular de participação nos assuntos humanos, uma nova estrutura era moldada sem necessariamente ter como base as experiências de conselhos anteriores. É a própria Arendt que lista o aparecimento dessas estruturas ao longo da história pós-revolucionária na França e nos Estados Unidos.

[...] as principais datas de aparecimento desses órgãos de ação e germes de um novo Estado são as seguintes: o ano de 1870, quando a capital francesa sitiada pelo Exército prussiano "e organizou espontaneamente num corpo federal em miniatura", que depois veio a formar o núcleo do governo da Comuna de Paris na primavera de 1871; o ano de 1905, quando a onda de greves espontâneas na Rússia de súbito desenvolveu uma liderança política própria, fora de todos os grupos e partidos revolucionários, e os operários das fábricas se organizaram em conselhos, os sovietes, para uma autogestão representativa; a Revolução de Fevereiro de 1917 na Rússia, quando "apesar das diferentes tendências políticas entre os trabalhadores russos, a organização em si, isto é, o soviete, nem sequer foi posta em discussão"; os anos de 1918 e 1919 na Alemanha, quando após a derrota do Exército, soldados e trabalhadores em rebelião aberta se constituíram em Arbeiter-und Soldatenräte, exigindo em Berlim que esse Rätesystem se tornasse a pedra fundamental da nova Constituição alemã estabelecendo, junto com os boêmios dos cafés em Munique, na primavera de 1919, a efêmera Räterepublick bávara; e, por fim, o outono de 1956, quando a Revolução Húngara, desde o início, criou novamente o sistema de conselhos em Budapeste, de onde se propagou por todo o país "com incrível rapidez". (ARENDT, 2011, p. 328, grifos nossos)

Estes são apenas os aparecimentos mais significativos dessa estrutura, apesar disso, a autora lista outra variedade de experiências que surgem na esteira da experiência dos conselhos revolucionários franceses e americanos, porém, com menor consciência política6 ${ }^{\text {. Assim }}$ sendo, Arendt quer salientar que parece haver uma conjunção entre o espírito revolucionário

\footnotetext{
6 "Na Alemanha Oriental, uma espécie de sistema cooperativo, que não provêm de modo algum do socialismo e que provou ter valor na Dinamarca e em Israel, foi construído no sistema econômico 'socialista' - fazendo com isto que ele funcionasse. Na Iugoslávia temos o 'sistema de autogerência' nas fabricas, uma nova versão dos antigos 'conselhos dos trabalhadores', que incidentalmente também nunca foi parte da doutrina ortodoxa comunista ou socialista - a respeito do 'todo poder aos soviéticos' de Lenin. (Os Conselhos, o único fruto genuíno das revoluções em si, e não dos partidos revolucionários e ideologias, foram impiedosamente destruídos exatamente pelo partido comunista e pelo próprio Lênin)" (ARENDT, 2015, p. 186).
} 
e as formas de organização popular que surgem constantemente. "Assim, o sistema de conselho parece corresponder e brotar da própria experiência da ação política" (ARENDT, 2015, p. 199).

Falando da Revolução Húngara, episódio que Arendt mais se debruça sobre os sistemas de conselho, depois das revoluções americana e francesa, a pensadora retoma e realça ainda mais esse caráter originário de irrupção do curso normal da história. Para ela, "esse evento não foi preparado, de forma alguma, pelos acontecimentos na Polônia. Ele foi totalmente inesperado e surpreendeu a todos [...]" (ARENDT, 2018b, p. 29). Um dos fatores mais significativo para Arendt em relação aos episódios dos conselhos na Hungria é que eles são a expressão prática de que o antigo medo de que uma forma de organização conduzida pelo povo pudesse se transformar em um estado de desordem ${ }^{7}$. Nas palavras da autora,

Em sua acepção mais positiva, o atributo excepcional do levante foi que nenhum caos decorreu das ações de um povo sem liderança e sem um programa previamente formulado [...]. Ao invés do domínio descontrolado das massas, que se poderia ter esperado, apareceram imediatamente, quase simultaneamente ao próprio levante, os Comitês Revolucionários e os Conselhos dos Trabalhadores. Ambos reproduzem uma nova forma de exercício da política - o sistema de conselhos - que, já há mais de cem anos, tem surgido sempre que é permitido ao povo seguir, por alguns dias, semanas ou meses, suas próprias estratégias políticas sem a imposição de um governo [...]. (ARENDT, 2018b, p. 76-77)

A Revolução Húngara figura no pensamento de Arendt como uma superação de algumas críticas feitas ao sistema de conselhos conforme apresentados nas revoluções americanas e francesa. É interessante o fato de que nesse episódio específico Arendt vê algo semelhante ao que Rosa Luxemburgo havia teorizado com o título de "revolução espontânea"8. Por revolução espontânea, Luxemburgo, segundo Arendt, entendia um levante popular pautado única e

\footnotetext{
7 "Os conselhos, no que se distinguem dos partidos, sempre surgiram durante a própria revolução e brotaram do povo como órgãos espontâneos de ação e de ordem. Vale frisar este último ponto; com efeito, nada contraria mais incisivamente o velho adagio das inclinações 'naturais' anarquistas e sem lei de um povo isento da coerção do governo do que o surgimento dos conselhos, que, sempre apareceram, e de modo mais acentuado durante a Revolução Húngara, estavam empenhados na reorganização da vida política e econômica do país e no estabelecimento de uma nova ordem" (ARENDT, 2011, p. 339).

8 "Se já existiu algo como a 'revolução espontânea' de Rosa Luxemburgo, então tivemos o privilégio de testemunhálo - esse levante repentino de um povo oprimido, em nome da liberdade, e não de outra coisa, que não foi precedido pelo caos desmoralizante da derrota militar, sem técnicas de golpes de estado, sem um aparato coeso de organizadores e conspiradores, sem a propaganda debilitante de um partido revolucionário [...]" (ARENDT, 2018b, p. 30).
} 
exclusivamente pelo desejo de liberdade, de participação nos assuntos públicos. Descrevendo esse processo do levantar-se espontaneamente, Arendt afirma:

\begin{abstract}
Uma manifestação estudantil desarmada e essencialmente inofensiva cresceu, repentina e espontaneamente, de alguns milhares para uma multidão imensa que se incumbiu de levar adiante uma das demandas dos estudantes, a de derrubar a estátua de Stalin em uma das praças públicas de Budapeste. No dia seguinte, alguns estudantes foram à Rádio Budapeste a fim de persuadir a estação a transmitir os dezesseis pontos do manifesto. Uma grande multidão se aglomerou imediatamente, como se surgisse do nada, e quando a ÁVH - a polícia que protegia o prédio - tentou dispersar o grupo com alguns tiros, a revolução estourou. As massas atacaram a polícia e conseguiram suas primeiras armas. Os trabalhadores, ao ouvirem sobre a situação, deixaram as fábricas e se juntaram à multidão. 0 exército, chamado para defender o regime e ajudar a polícia armada, se juntou à revolução e armou o povo. 0 que começara como uma manifestação estudantil se tornou um levante armado em menos de 24 horas (ARENDT, 2018b, p. 72-73).
\end{abstract}

Iniciada nas mãos do movimento estudantil, logo o que antes era expressão apenas de um seguimento da sociedade, ganhou forma plural e assumiu a bandeira da liberdade e da verdade como as pautas mestras desse agir. Sabe-se que Lênin e o governo russo agiam de maneira consistente para manipular as informações (ARENDT, 2011, p. 323), e é nesse contexto que a verdade, que naturalmente não fazia parte das reivindicações revolucionárias, aparece aos revolucionários. "Enquanto a liberdade dizia respeito ao direito de tomar parte nos assuntos comuns, a verdade consistia em combater a ideologia soviética e em denunciar a ditadura totalitárias que dominava os países satélites" (RUBIANO, 2016, p. 223). Esse acréscimo da reivindicação pela liberdade só confirma a tese arendtiana de que a cada surgimento dos conselhos uma nova forma e uma nova estrutura são apresentadas, ao mesmo tempo em que lança luz sob esse aspecto da ação heroica e espontânea.

Assim, "entre as características mais comuns aos conselhos, a mais destacada é, claro, a espontaneidade com que surgem [...]" (ARENDT, 2011, p. 329). Esses conselhos húngaros são a demonstração da ideia de que no interior das revoluções já surge um movimento que propõe uma nova forma de organização, se opondo a organização do Estado Nacional. "Esses conselhos húngaros são apresentados pela autora como fator de esperança para a instauração de uma novidade em termos de estruturas políticas" (OLIVEIRA, 2009, p. 270).

Tendo compreendido o caráter espontâneo de seu surgimento, é possível agora perceber que o que movia os participantes desse conselho era o desejo de participação nos assuntos 
humanos, o gosto pela liberdade. Na medida em que essas estruturas normalmente se tornam pilares da Constituição, de modo específico no caso norte-americano, elas assumem na prática a principal preocupação da Constituição, que é a preservação da liberdade. Consequentemente “[...] quem interferisse com suas reuniões estaria 'atacando a liberdade' e, entre os crimes contra a revolução, 'o maior era a perseguição às sociedades'” (ARENDT, 2011, p. 303).

Essa relação e consciência de que esses espaços concretizavam de fato a liberdade que estava sendo a fonte do movimento revolucionário era fruto da sabedoria dos antigos que afirmava a necessidade de um espaço tangível para que a liberdade pudesse realmente ser experimentada (RUBIANO, 2016, p. 75). Esse espaço era, conforme caracterizamos na primeira parte deste texto, um lugar onde todos pudessem falar e agir de modo espontâneo e em conjunto, lugar da manifestação da pluralidade.

Por enquanto, ficamos com o destaque dado pela autora para o fato de que os conselhos eram, enquanto existiam, um espaço privilegiado para todos aqueles que desejassem se engajar no campo dos assuntos humanos (ARENDT, 2011, p. 329). Em determinada medida, esse desejo de participar dos assuntos humanos reedita aquele desejo do herói homérico de imortalizar-se que, segundo Arendt, fora percebido como sendo possível somente através da ação e do discurso. Nas palavras da autora,

Se o fim último da revolução era a liberdade e a constituição de um espaço público onde a liberdade fizesse sua aparição, a constitutivo libertatis, então as repúblicas elementares dos distritos, único local tangível onde cada um podia ser livre, efetivamente constituíam a finalidade da grande república, cujo principal propósito nos assuntos internos deveria consistir em oferecer ao povo esses locais de liberdade e protegê-los adequadamente. 0 pressuposto básico do sistema distrital, soubesse Jefferson ou não, era que ninguém poderia se dizer feliz sem ter sua parcela na felicidade pública, ninguém poderia se dizer livre sem ter sua experiência própria na liberdade pública, ninguém poderia se dizer feliz ou livre sem participar e ter uma parcela no poder público. (ARENDT, 2011, p. 320)

André Duarte vê nessas experiências um feixe de luz do sentido original da política. Para ele, a pensadora concebeu essas estruturas “[...] como encenações da política em suas manifestações greco-romanas originarias, estabelecendo desse modo 'correspondances estre coisas fisicamente as mais remotas entre si' [...]" (DUARTE, 2000, p. 264). Em outros termos, dizemos que Arendt percebeu na experiência dos conselhos uma reedição das manifestações originárias 
da política, e que esse vínculo entre as duas experiências jamais fora levado em consideração pela tradição de pensamento ocidental. É como se ela conseguisse perceber um elo entre a compreensão heroica do agente político e o surgimento espontâneo dessas estruturas ignoradas pela traição.

Porém, para que não se caia em contradição com o que Arendt tratou sobre a dimensão inédita desses eventos, é necessário usar do argumento de Mariana Rubiano para a questão da mutação dos conceitos ao longo do pensamento de Arendt. Para a pesquisadora, Hannah Arendt "[...] busca a genealogia dos conceitos, mas isso não significa que a origem aponta para a ontologia, uma vez que o conceito possui historicidade: seu significado mais recente pode ultrapassar sua origem" (RUBIANO, 2016, p. 18). Por conseguinte, a realidade dos conselhos possui dignidade própria apesar do elo que possui com as manifestações originarias da antiguidade.

Nesse sentido, parece haver um pouco de como Arendt pensou no verso de Ferreira Goullart utilizado no início deste ensaio. Apesar de Arendt já ter localizado algo similar ao que fora vivido nos sistemas de conselho naquela literatura de Homero, não é suficiente perceber esse novo evento como repetição, isso "não satisfaz a vida” do espírito publico. É preciso viver esse espírito publico e a ele acrescentar algo de novo através da atividade que para Hannah Arendt é, dentre todas, a mais humana: a ação não soberana.

\section{Referências}

ARENDT, Hannah. A condição humana. Trad. Roberto Raposo. 13. ed. rev. Rio de Janeiro: Forense Universitária, 2016a.

ARENDT, Hannah. A promessa da política. Ed. Jerome Kohn. Trad. Pedro Jorgensen Jr. 4. ed. Rio de Janeiro: Difel, 2016b.

ARENDT, Hannah. A vida do espírito: o Pensar, o Querer e o Julgar. Trad. Antônio Abranches e Helena Martins. Rio de Janeiro: Relume Dumará, 2002.

ARENDT, Hannah. Imperialismo totalitário: reflexões sobre a revolução húngara. In: ARENDT, Hannah. Ação e a busca da felicidade. Org. Heloisa Starling; Trad. Virginia Starling. 2. ed. Rio de Janeiro: Bazar do tempo, 2018b, p. 21-112.

ARENDT, Hannah. Entre o passado e o futuro. Trad. Mauro Barbosa. 7. ed. São Paulo: Perspectiva, 2014.

ARENDT, Hannah. Reflexões sobre a política e revolução: um comentário. In: ARENDT, Hannah. Crises da República. Trad. José Volkmann. 3. ed. São Paulo: Perspectiva, 2015, p. 171-201.

ARENDT, Hannah. Sobre a Revolução. Trad. Denise Bottmann. São Paulo: Companhia das Letras, 2011. 
ALVES NETO, Rodrigo Ribeiro. Alienação do mundo: uma interpretação da obra de Hannah Arendt. Rio de Janeiro: Loyola/ PUC-RIO, 2009.

COURTINE-DÉNAMY, Sylvie. O cuidado com o mundo: diálogo entre Hannah Arendt e alguns de seus contemporâneos. Trad. Maria Juliana Gambogi Teixeira, Belo Horizonte: Ed. UFMG, 2004.

DUARTE, André. O pensamento à sobra da ruptura: política e filosofia em Hannah Arendt. São Paulo: Paz e Terra, 2000.

FRANCISCO, Maria de Fátima Simões. A pólis Homérica como modelo da polis grega arendtiana. In: MULLER, Maria Cristina. Anais [do] VII Encontro Hannah Arendt \& IV Ciclo Hannah Arendt. Londrina: UEL, 2013, p. 188-200.

HOMERO. Odisseia. Trad. Manoel Odorico Mendes. São Paulo: Ed. Atenas, 2009.

HOMERO. Ilíada. Trad. Manoel Odorico Mendes. São Paulo: Ed. Atenas, 2009.

OLIVEIRA, José. A estrutura de organização do corpo político na concepção de Hannah Arendt. Revista de Filosofia Unisinos, v. 3, n. 10, 2009, p. 265-277

RUBIANO, Mariana de Matos. Revolução em Hannah Arendt: compreensão e história. Tese (Doutorado em Filosofia) - Faculdade de Filosofia, Letras e Ciências Humanas da USP. São Paulo, 2016.

Recebido em: 24/10/2021

Aprovado em: 08/12/2021

\section{Carlos Fernando Brito Silva}

Doutorando em Filosofia pela UFMG, mestre em Filosofia pela UFPI, graduado em Filosofia na Faculdade Católica do Maranhão - IESMA, Bolsista FAPEMA (BD-02532/21). 